ORIGINAL ARTICLE

AFRICAN JOURNAL OF CLINICAL AND EXPERIMENTAL MICROBIOLOGY $\quad$ MAY $2013 \quad$ ISBN 1595-689X $\quad$ VOL 14(2) 2013

AJCEM/21310 -http://www.ajol.info/journals/ajcem

AFR. J. CLN. EXPER. MICROBIOL 14(2): 51-55 http:/ / dx.doi.org/10.4314/ajcem.v14i2.2

\title{
LIPID PROFILE OF DRUG NAIVE HIV PATIENTS IN A TERTIARY HEALTH FACILITY IN LAGOS, NIGERIA
}

\author{
${ }^{*}$ Uwandu, M.O. ${ }^{1}$ Okwuraiwe, A.P. ${ }^{1}$, Amoo, O.S. ${ }^{1}$ Audu, R.A., ${ }^{1}$ Okoye, R.N. ${ }^{2}$, Oparaugo, C.T. ${ }^{2}$, Onwuamah, C.K. ${ }^{1}$ and \\ Magbagbeola O.A. ${ }^{3}$ \\ 1. Human Virology Laboratory, Nigerian Institute of Medical Research, Yaba, Lagos, Nigeria \\ 2. Clinical Diagnostic Laboratory, Nigerian Institute of Medical Research, Yaba, Lagos, Nigeria \\ 3. Biochemistry Department, College of Medicine, University of Lagos, Idi-Araba, Lagos, Nigeria. \\ *Correspondence: azukaokwu@yahoo.com; uwandumabel@yahoo.com
}

\section{ABSTRACT}

Aim: To determine the effect of HIV syndrome on lipid profile in a cohort of Nigerians.

Objective: To determine the concentrations of total cholesterol (Tchol), triglyceride (TGL), high density lipoprotein (HDL), and low density lipoprotein (LDL) in HIV positive drug naive patients as against HIV negative people.

Methods: This study examined the lipid profiles of $50 \mathrm{HIV}$ positive individuals (test group), and $50 \mathrm{HIV}$ negative individuals (control group) at the Human Virology Laboratory of Nigerian Institute of Medical Research (NIMR), Lagos, Nigeria. Informed consent was obtained and the Institutional Review Board (IRB) of NIMR approved the study. A questionnaire based assessment was provided for the individuals to complete, before $5 \mathrm{ml}$ of blood was taken by venopuncture. Blood collected in plain tubes was centrifuged at $3500 \mathrm{rpm}$ for $\mathbf{1 0}$ minutes and the serum obtained, used for the various lipid profile tests mentioned above. Statistical analysis on data from the questionnaire was done using Epi info 2000 (CDC).

Results: The median lipid profile values for the control group were 168, 85, 99 and $58 \mathrm{mg} / \mathrm{dl}$ for Tchol, TGL, HDL and LDL respectively. Conversely, median lipid profile values for the HIV positive patients were 145, 98, 53, and $67 \mathrm{mg} / \mathrm{dl}$ for Tchol, TGL, HDL and LDL respectively. P values greater than 0.05 were taken to indicate an insignificant difference between the lipid profiles of the two groups.

Conclusion: Based on results obtained, there were significant differences in the Tchol and HDL values between the two groups, indicating a possible effect of HIV on lipid profile for drug naive patients.

Key words: lipid profile, HIV, TGL, HDL, LDL, Tchol.

\section{INTRODUCTION}

Lipids, a diverse group of compounds which serve as storage compounds, structural components, cofactors and pigments, are found almost universally as stored forms of energy in living organisms as derivatives of fatty acids. Phospholipids and sterols are components of cell membranes [1]. Some serve as hormones, or as intracellular messengers generated in response to an extracellular signal. Others function as enzyme cofactors in electron-transfer reactions in chloroplasts and mitochondria [1]. Fairly current knowledge regarding the etiology of altered lipid metabolism in HIV-positive patients does not afford a clear picture as to whether HIV disease itself or antiretroviral therapy (ART) is largely to blame; there are proponents on each side of the debate [2].
HIV-infected individuals, both those on ART and those who are untreated, appear to have higher rates of coronary heart disease (CHD) than HIV-uninfected individuals and higher rates of various risk factors for CHD, including dyslipidemia. HIV itself causes lipid perturbations, particularly in persons with more advanced immunosuppression; HIV-infected individuals who are not on antiretroviral (ARV) medications often have elevations in triglyceride (TG) levels and decreases in high-density lipoprotein (HDL) as well as in low-density lipoprotein (LDL) and total cholesterol (TC). Lipid abnormalities also may be caused by or compounded by ARVs [3].

Studies on lipid profile have focused on antiretroviral drug-induced lipid changes of HIV infected people. 
Findings have been controversial, with some studies stating an increased lipid profile [4,5], and others reduced levels of some lipids. Few studies have documented drug naive lipid profile changes.

Cases of AIDS have been reported in every nation of the world, yet the disease affects some countries more than others. More than 95\% of all HIV-infected people live in the developing world [6,7]. The use of effective ART has resulted in tremendous improvements in morbidity and mortality of HIV-infected individuals [7]. However there have been various studies linking HIV antiretroviral therapy with excess lipid depositions and abnormalities [8]. The widespread use of effective ART regimens has coincided with increasing reports of metabolic abnormalities such as impaired glucose metabolism and insulin resistance, lactic acidosis, osteopenia, and dyslipidemia [8].

Nutrition is of vital importance because it improves resistance and slows the progression of AIDS. Nutritional needs of HIV patients include increased intake of protein, vitamins, minerals and enough kilocalories to prevent weight loss and to meet increased metabolic demands.

Although lipid metabolism in HIV patients on ART and drug naive HIV patients (much less) has been widely studied across the globe, none to our knowledge has been done in our locality. Hence this study was undertaken to investigate the lipid profile of HIV patients, to assess if HIV infection is implicated in aggravating the normal lipid profile of Nigerians living with HIV.

\section{METHODS}

\section{STUDY POPULATION}

This was a case controlled study carried out between HIV positive drug naive and HIV negative persons. Recruitment period was from May to July, 2010. One hundred individuals were recruited, whose ages ranged between 20 to 55 years, with a mean of 34.2 years. Fifty HIV positive and 50 HIV negative, apparently healthy individuals were recruited from the Human Virology and the Clinical Diagnostic Laboratories of the Nigerian Institute of Medical Research (NIMR) Yaba, Lagos, Nigeria. The individuals were randomly selected using a simple random sampling technique. The HIV negative persons were mostly Staff and Interns of the two laboratories. Inclusion criteria for the study were HIV seropositivity and antiretroviral naive status with clinical/laboratory stage of CD4 above 350 cells/ $\mu 1$ and HIV viral load less than 400 RNA copies/ml.

\section{ETHICAL CLEARANCE; INFORMED CONSENT}

Ethical clearance was obtained from the Institutional Review Board of NIMR. Informed consent of patients was obtained before including them in the study. The study did not interfere with clinical management and the confidentiality of patients was maintained by deidentifying the specimens.

\section{QUESTIONNAIRE DISTRIBUTION}

Copies of a questionnaire were distributed to the 100 people, where data on physical parameters, (age, sex, etc) eating habits before and after HIV diagnosis were collected. The Control group (50) did not answer the 'After diagnosis' section of the questionnaire. The questionnaires were collected after filling, entered and analyzed by Epi Info 2000 (CDC).

\section{COLLECTION OF BLOOD SAMPLES}

Five $\mathrm{ml}$ of blood was collected by clear venopuncture into plain vacutainers. The samples were centrifuged for 10 minutes at a speed of 3,500 rpm and the serum separated.

\section{CHOLESTEROL ANALYSIS}

Cholesterol was determined by enzymatic colorimetric method of Randox (United Kingdom) [9]. The cholesterol is determined after enzymatic hydrolysis and oxidation. The indicator quinoneimine was formed from hydrogen peroxide and 4aminoantipyrine in the presence of phenol and peroxidase to give a pinkish coloration.

\section{TRIGLYCERIDE ANALYSIS}

Triglyceride was determined using Randox kits; a lipoprotein lipase from microorganisms for the rapid and complete hydrolysis of triglycerides to glycerol followed by oxidation to dihydroxyacetone phosphate and hydrogen peroxide which reacts with 
4-aminophenazone and 4-chlorophenol under the catalytic action of peroxidase to form a red dye (Trinder endpoint reaction).

\section{LOW DENSITY LIPOPROTEIN ANALYSIS}

LDL was determined using a direct method (Randox). This method takes advantage of the selective micellary solubilisation of LDL by a nonionic detergent and the interaction of a sugar compound and lipoproteins (VLDL and chylomicrons).

\section{HIGH DENSITY LIPOPROTEIN ANALYSIS}

HDL was determined by an enzymatic colorimetric method (Randox). This method uses polyethylene glycol-modified enzymes and dextran sulfate. When cholesterol esterase and cholesterol oxidase enzymes are modified by PEG, they show selective catalytic activities toward lipoprotein fractions, with the reactivity increasing in the order: $\mathrm{LDL}<\mathrm{VLDL} \approx$ chylomicrons $<$ HDL.

\section{RESULTS}

Mean weight was $67.3 \mathrm{~kg}$ for the control group (HIV-) and $62.6 \mathrm{~kg}$ for the test group (HIV+), giving an insignificant difference $(p>0.05)$ between them. Their mean heights were $1.61 \mathrm{~m}$ and $1.63 \mathrm{~m}$ for the control and test groups respectively. Sex distribution male: female ratio was 15:35, and 26:24 for the test and control groups respectively. Mean age was 34.2 years for both the control group and HIV positive individuals. The marital status showed $64 \%$ and $54 \%$ were married; $36 \%$ and $42 \%$ were single; while $0 \%$ and $4 \%$ were separated for the test and control groups respectively (Table 1).

From analysis of the questionnaires, eating habits before diagnosis and after, showed a slight improvement towards healthy eating in the test group. Figure 1 presents the lipid profile of the two groups of people with normal ranges (low and high) beside each parameter. Median total cholesterol, triglyceride, HDL and LDL was 168, 85, 99 and 58 $\mathrm{mg} / \mathrm{dl}$ for the control group respectively; and 145, 98, 53 and $67 \mathrm{mg} / \mathrm{dl}$ for the test group respectively (Table 2).

\section{DISCUSSION AND CONCLUSION}

In this study, lipid profile was comparatively analyzed for $50 \mathrm{HIV}$ positive and $50 \mathrm{HIV}$ negative individuals in Lagos, South-western Nigeria. Both groups were closely matched in their mean ages (both 34.2 years). Heights and weights were also in general, fairly average. Body Mass Index (BMI) was 23.5 and 25.7 for the HIV positive and negative groups respectively. This ironically shows an apparently healthy HIV positive group and a slightly overweight HIV negative group. The observed differences in the values obtained after data analysis were statistically significant $(\mathrm{p}<0.05)$ for two of the parameters tested, Tchol and HDL, but insignificant for TGL and LDL. Significantly higher Tchol and HDL values were observed for the HIV negative group than the positive group.

These findings may be a factor pointing towards an initiation of body fat redistribution in the HIV infected people. Altered lipid metabolism is known to affect immune processes. Caraciolo et al [10] characterized the lipid profile of asymptomatic untreated HIV positive individuals compared with a control group. They investigated the relationship between serum lipid levels and CD4 lymphocytes (CD4) and viral load (VL) of asymptomatic untreated HIV positive men who have sex with men (MSM),

TABLE 1: PHYSICAL PARAMETERS OF THE 50 HIV POSITIVE (TEST) AND 50 HIV NEGATIVE (CONTROL) GROUPS

\begin{tabular}{|c|c|c|c|}
\hline PARAMETER & HIV positive & HIV negative & P value \\
\hline mean Weight (kg) & 62.6 & 67.3 & 0.05 \\
\hline mean Height (m) & 1.63 & 1.62 & 0.53 \\
\hline mean Age (years) & 34.2 & 34.2 & 0.98 \\
\hline Sex (N): male & 15 & 26 & - \\
Female & 25 & 24 & - \\
\hline Marital status (\%) & & & - \\
Married & 64 & 54 & - \\
Single/Separated & 36 & 42 & \\
& & & \\
\hline
\end{tabular}


TABLE 2: LIPID PROFILE OF THE 50 HIV POSITIVE PATIENTS AND 50 NEGATIVE CONTROL GROUPS (*- statistically significant)

\begin{tabular}{|c|c|c|c|}
\hline PARAMETER & HIV Positive & HIV Negative & P value \\
\hline median TChol $(\mathrm{mg} / \mathrm{dl})$ & 145 & 168 & $0.001^{*}$ \\
\hline median TGL $(\mathrm{mg} / \mathrm{dl})$ & 98 & 85 & 0.105 \\
\hline median HDL (mg/dl) & 53 & 99 & $0.000^{*}$ \\
\hline median LDL (mg/dl) & 67 & 58 & 0.614 \\
\hline
\end{tabular}

comparing it with a control group, in Spain. They stated that the slightly lowered lipid variations observed, excluding antiretroviral therapy, hepatic and nutritional effects might be due to HIV action. This study however does not support this assumption.

Elevations in serum TChol and TGL levels, along with dyslipidemia that typically occur in patients with HIV infection, may predispose patients to complications such as premature atherosclerosis, particularly coronary heart disease, and pancreatitis [11]. It remains to be seen if lipid metabolism is altered at initiation of antiretrovirals (PI- or NNRTI-based) as reported in a study [8]. Adewole et al, [12] stated that abnormalities in serum lipid are common among treatment naive HIV patients. The results obtained here are in partial support to that of Adewole et al [12]. In conclusion, in this study the presence of HIV infection affected some of the lipid profile parameters of the patients tested (altered cholesterol and HDL).

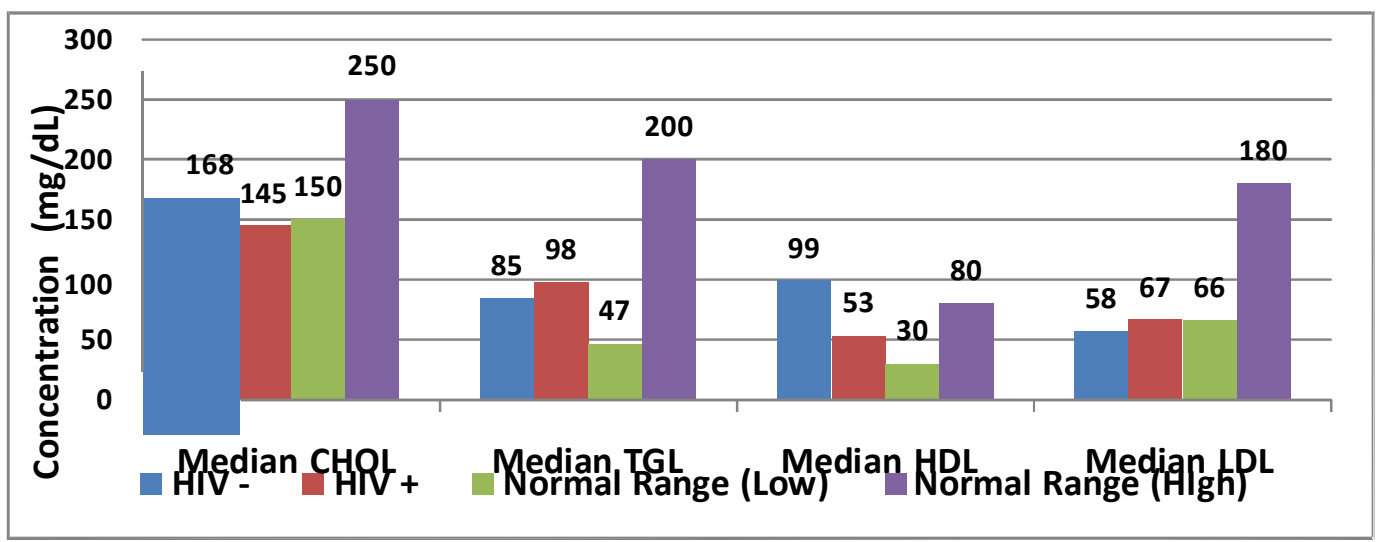

Figure 1: The median lipid profile of the HIV positive (test) and the HIV negative (control) groups

These findings however may be inconclusive due to the relatively small sample size utilized in this study. A broader study, involving the immunologic parameters (CD4, CD8), and viral load is recommended to further validate the findings of this study.

\section{REFERENCES}

1. Gurr, MI and Harwood JL. (1991) Lipid Biochemistry: An Introduction, 4th edition, Chapman \& Hall, London. A good general resource on lipid structure and metabolism, at the intermediate level.
2. Oduola T, Akinbolade AA, Oladokun LO, Adeosun OG, Bello IS, and Ipadeola TI. (2009). Lipid Profiles in People Living with HIV/AIDS on ARV Therapy in an Urban 
Area of Osun State, Nigeria. World Journal of Medical Sciences 4 (1): 18-21.

3. Chow DC, Day LJ, Souza SA, and Shikuma CM. (2003). Metabolic complications of HIV therapy. HIV Clin Trials; 4(6):411416.

4. Hui DY (2003). Effects of HIV protease inhibitor therapy on lipid metabolism. Progress in Lipid Research Vol 42, Issue 2, Pages 81-92

5. Hogg RS, Heath KV, Yip B, Craib KJP, O'Shaughnessy MV, Schechter MT, Montaner, JSG. (1998). Improved survival among HIV-infected individuals following initiation of antiretroviral therapy. JAMA, 279:450-454.

6. Fauci AS. (1999). The AIDS epidemic. Considerations for the 21st century. N Engl J Med, 341:1046-1050.

7. Summerbell CD, Perret J and Gizzard BG. (1993). Causes of weight loss in human immunodeficiency virus infection int. J STD \& AIDS; Int J STD AIDS. Jul-Aug; 4(4):234-6.

8. Young J, Weber R, Rickenbach M, Furrer $\mathrm{H}$, Bernasconi E, Hirschel B, Tarr PE, Vernazza P, Battegay $\mathrm{M}$ and Bucher $\mathrm{HC}$. (2005). Lipid profiles for antiretroviralnaive patients. Antivir Ther; 10 (5): 585-91.
9. Trinder P. (1969). Reagent for enzymatic determination of cholesterol with improved lypolytic efficiency. Ann Clin Biochem; 6; 24-25.

10. Caraciolo BB, Alonso J, Carrio Montiel D, del Corral del Campo S, Molina AQ, Heredero SM, Garcia PS, del Romero GJ. (2002). International Conference on AIDS. Int Conf AIDS; 7-12; 14: abstract no. ThPeB7325.

11. Dube MP, Sprecher D, Henry WK, Aberg JA, Torriani FJ, Hodis HN, Schouten J, Levin J, Myers G, Zackin R, Nevin T, and Currier JS. (2003). Preliminary guidelines for the evaluation and management of dyslipidemia in adults infected with human immunodeficiency virus and receiving antiretroviral therapy: Recommendations of the Adult AIDS Clinical Trial Group Cardiovascular Disease Focus Group. Clin Infect Dis; 31:1216-24.

12. Adewole OO, Eze S, Betiku Y, Anteyi E, Wada I, Ajuwon Z and Erhabor G. (2010). Lipid profile in HIV/AIDS patients in Nigeria. Afr Health Sci; 10 (2): 144-9. 